\title{
VARIA
}

\section{A PROPÓSITO DE UNAS VERSIONES DE LA SAGRADA FAMILIA CON LOS SANTOS «UUANITOS» DE JUAN DE JUANES}

Desde el año 1961 consta en el Archivo fotográfico del Instituto Amatller de Barcelona una Sagrada Familia con los santos «Juanitos» (fig. 1), en colección privada madrileña ${ }^{1}$. Un año después, José Luis Alonso Misol la publicó en un artículo sobre Pintura española en colecciones madrileñas ${ }^{2}$, aportando el nombre del coleccionista, Sr. Fernández López, y destacando que se trataba de una de las mejores obras de Juan de Juanes, de la que hay otras versiones con algunas variantes, poniendo como ejemplo de ellas la de la Academia de San Fernando (fig. 3). En esta línea podría considerarse la pintada por Nicolás Borrás (fig. 4), de la colección Grases de Barcelona ${ }^{3}$, donde se encontraba en 1916, y en la que se advierten ambas influencias.

En el año 1979 José Albi publica su libro de Joan de Joanes dando a conocer otra versión similar a la de la colección madrileña de Fernández López, con variantes relativas al paisaje - menos minucioso - en el que la figura del pequeño San Jerónimo, junto a la arboleda de la pirámide, se halla dentro de una cueva (fig. 5). Esta versión la localiza en la colección Rojas de Alicante ${ }^{4}$.

En el año 1966, se expone en la Sala Parés de Barcelona, la Sagrada Familia que Misol publicó de la colección López Fernández (fig. 1). La galería Parés reproduce el texto de Misol y pone como procedencia de la tabla la antigua colección Bernstein de Madrid ${ }^{5}$.

Recientemente ha aparecido en el comercio madrileño una nueva versión del tema (fig. 2), de la que existía fotografía en el Archivo Moreno de Madrid (fig. 6), procedente del Servicio de Recuperación del año 1941 sin indicar localización ${ }^{6}$. Esta versión presenta más similitudes con la versión de la colección Rojas de Alicante en cuanto al paisaje —insistimos, menos mi-

\footnotetext{
1 Archivo Amatller. Cliché n. ${ }^{\circ}$ G. 46259.

${ }^{2}$ Goya, 1962, n. ${ }^{\circ}$ 50-51, pág. 163.

${ }^{3}$ Atribuida a este pintor por M. Díaz Padrón y A. Padrón Mérida en «Pintura valenciana del siglo xvi. Aportaciones y precisiones», Archivo Español de Arte, 1987, págs. 105-136, considerándola también como derivación de la de la Academia de San Fernando. En el Archivo Amatller aparece con el $\mathrm{n}^{\circ} \mathrm{C}-14040$, indicando que la composición original de la escuela de Bolonia se hallaba en Previlatti.

${ }^{4}$ Valencia, Institución Alfonso el Magnánimo. Tomo II, pág. 235-236, lam. CCV.

${ }^{5} 107 \times 79 \mathrm{~cm}$. Catálogo Pinturas Españolas. Siglos XVI-XVII. Cuadros de colecciones españolas. XIV. Sala Parés, Barcelona, 1966, pág. 4, lám. 1.

${ }^{6}$ Archivo Amatller, cliché $n^{\circ}$ Z-10241. A propósito de un trabajo mío sobre «La Virgen y el Niño con los santos Juanitos, de Martín Gómez», Ars Longa, n 1, 1990, pág. 27-33, reproduje esta misma foto localizada en el departamento de Arte del C.S.I.C., como depósito del servicio de Recuperación. Al parecer ha sido adquirida por una colección privada valenciana. Las medidas son $117 \times 79 \mathrm{~cm}$.
} 



AEA, LXXV, 2002, 297, pp. 51 a 88 

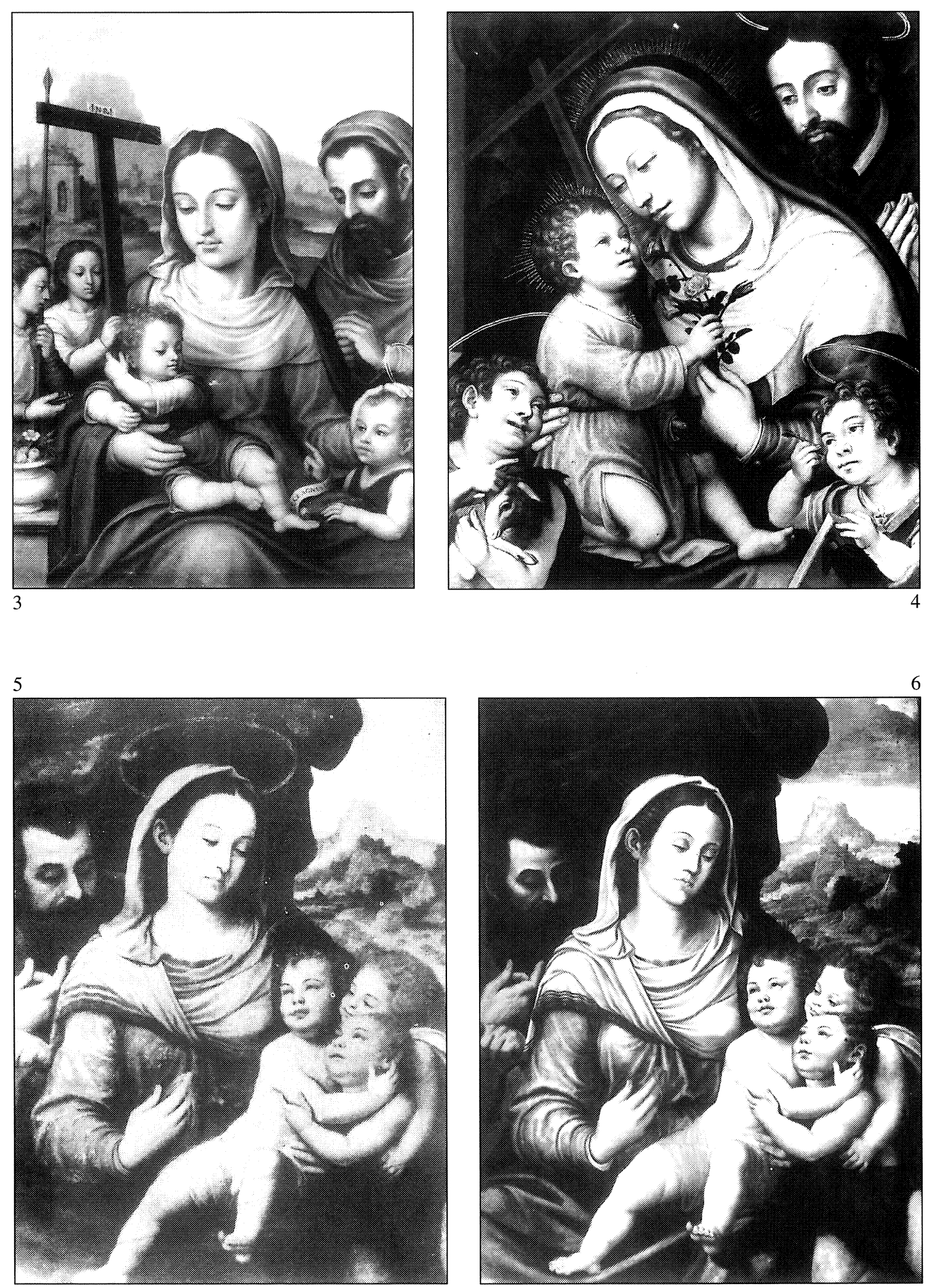

Fig. 3. Juan de Juanes. Sagrada Familia con el Bautista. Madrid, Academia de San Fernando. Fig. 4. Nicolás Borrás. Sagrada Familia con los Santos Juanitos. Barcelona, Col. Grases. Fig. 5. Juan de Juanes. Idem. Alicante, Col. Rojas. Fig. 6. Ver fig. 2.

AEA, LXXV, 2002, 297, pp. 51 a 88 

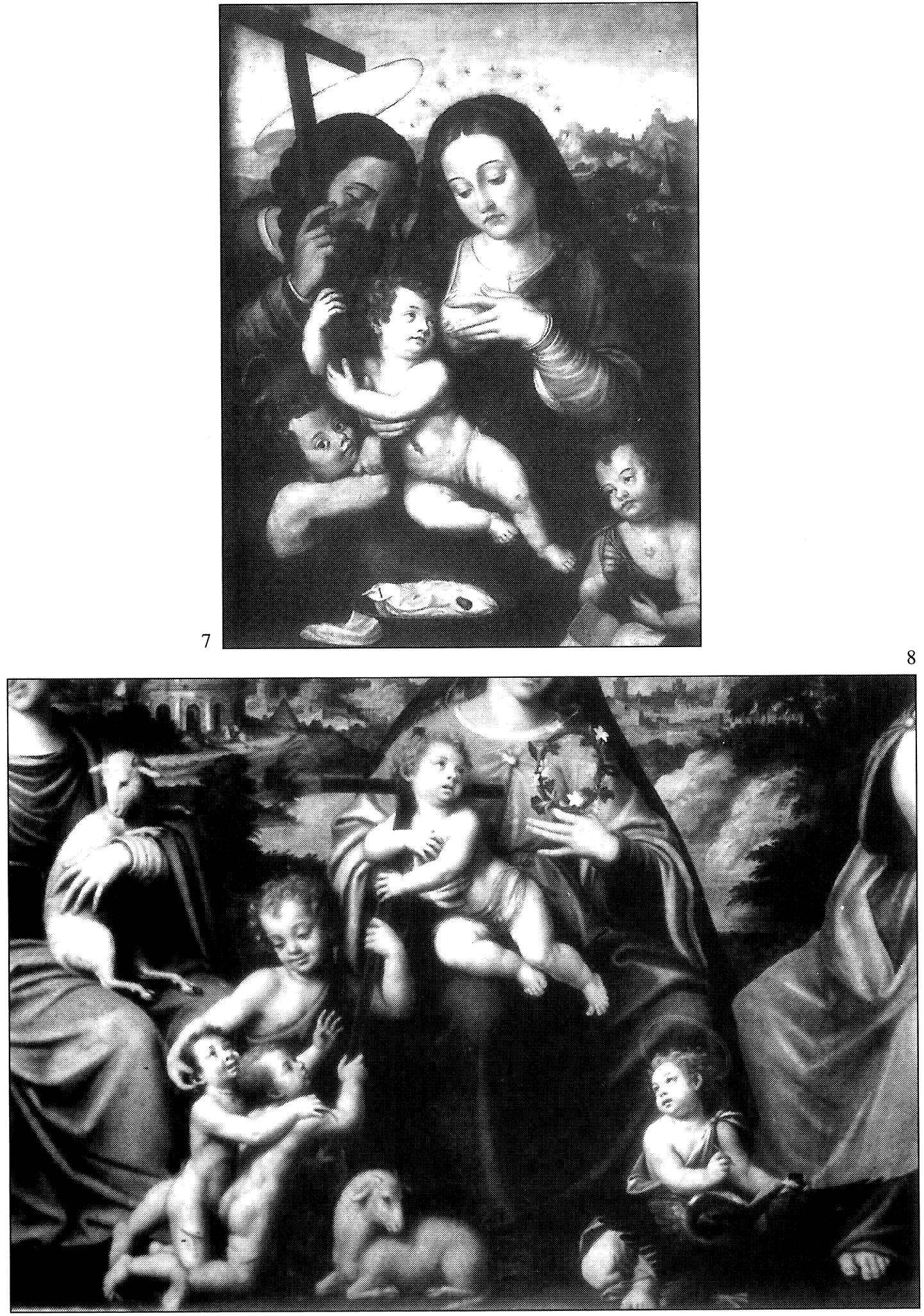

Fig. 7. Juan de Juanes, Sagrada Familia con los Santos Juanitos. Tortosa (Tarragona), Col. León.

Fig. 8. Juan de Juanes, Desposorios místicos con el Beato Aguesio (detalle). Valencia, Museo de San Pío V.

AEA, LXXV, 2002, 297, pp. 51 a 88 
nucioso- pero en el que, en cambio, la presencia de San Jerónimo es similar al ejemplar madrileño. Los nimbos de los niños, presentes en la versión Bernstein, casi no existen en la alicantina y han desaparecido en la recientemente aparecida, en la que también se hecha de menos la mano de Jesús sobre la parte posterior de la cabeza del evangelista niño, sustituida por una incipiente insinuación de un nimbo, tal vez debido a una restauración. La limpieza del cuadro recientemente aparecido en el comercio madrileño ha recuperado calidades en el sutil velo que cubría excesivamente el cuerpo del Niño Jesús (fig. 6), dejándolo al descubierto como en las otras versiones. Los modelos de la Virgen y el Niño nos evocan los de la Sagrada Familia de Juanes (fig. 7), de la colección León en Tortosa (Tarragona), mostrando ambas versiones una calidad algo menos suave que en las otras versiones, debido tal vez a la reciente limpieza y restauración de la versión localizada en el comercio madrileño.

El éxito del tema es evidente y no podemos sustraernos a la tentación de exponer la reinterpretación que de él hizo Juanes, en los Desposorios místicos con el Beato Agnesio (fig. 8), en que se suman, a la iconografía de los santos Juanitos, dos «santos inocentes» ${ }^{7}$, aportando interés iconográfico al tema pasionario.

IsABel Mateo Gómez Dpto. Arte. CSIC

\section{ESTEBAN JAMETE EN BURGOS}

En el mes de noviembre de 1535 Esteban Jamete, después de ganar el jubileo en Santiago de Compostela y estar unos días en Medina de Rioseco, se encaminó hacia Burgos. La presencia en esta ciudad del escultor Felipe Vigarny, compatriota suyo que gozaba de gran prestigio en Castilla y del que con toda seguridad había tenido noticia, fue probablemente la razón de su viaje.

Para Jamete su paso por esta ciudad, en la que con tanta fuerza había arraigado el arte flamenco y en la que con cierta lentitud se había adoptado el nuevo estilo que venia de Italia, fue sumamente enriquecedor, pues además de trabajar con Vigarny, uno de los introductores del Renacimiento en Burgos(aunque en sus primeros trabajos todavía se mostró muy apegado a formulas medievales), también pudo ver en la catedral burgalesa algunas de las obras más representativas del arte refinado y clásico de Diego de Siloe, cuya belleza, un artista como Jamete sin duda supo apreciar.

Al poco tiempo de llegar a Burgos, Jamete entró en el taller de Vigarny y durante los tres meses que duró su estancia en esta ciudad, según nos informa el propio artista ${ }^{1}$, estuvo en casa de mase Felipo a su oficio de entallador labrando de madera donde trabajo en fazer el modelo de las sillas de Toledo de la iglesia mayor. La labor realizada por Jamete debió de gustar a Vigarny, como lo demuestra el hecho de que cuando se procedió a ejecutar esta sillería, fue uno de los artífices que intervino en ella.

\footnotetext{
${ }^{7}$ Considerada por Tormo de la última etapa del pintor y por F. Benito Domenech entre 1553-1558. Este autor en Joan de Joanes. Las bodas místicas del venerable Agnesio. Valencia, Museo de Sant Pius V. 1996 y Exposición Joan de Joanes. Madrid-Valencia, 1979-1980, recoge la datación del cuadro por varios autores.

' Domínguez Ortiz, Proceso inquisitorial contra el escultor Esteban Jamete, Madrid, 1933, pp.24,25.
}

$A E A, \mathrm{LXXV}, 2002,297$, pp. 51 a 88 